\title{
$\beta$-Cyclodextrin Polyurethanes Copolymerised with Beetroot Fibers (Bio-Polymer), for the Removal of Organic and Inorganic Contaminants from Water
}

\author{
Jamil Rima $^{1} \&$ Karine Assaker ${ }^{2}$ \\ ${ }^{1}$ Physical Chemistry of Environmental Engineering and Biology Laboratory, Department of Chemistry, Faculty \\ of Sciences II, Lebanese University, Metn, Lebanon \\ ${ }^{2}$ Faculté des Sciences, Université de Lorraine - Nancy, Vandoeuvre-les-Nancy Cedex, France \\ Correspondence: Physical Chemistry of Environmental Engineering and Biology Laboratory, Department of \\ Chemistry, Faculty of Sciences II, Lebanese University, P. O. Box, Metn, Lebanon. E-mail: \\ jamil.rima1@gmail.com
}

Received: November 21, 2012 Accepted: December 27, 2012 Online Published: January 27, 2013

doi:10.5539/jfr.v2n1p150

URL: http://dx.doi.org/10.5539/jfr.v2n1p150

\begin{abstract}
In this study, $\beta$-Cyclodextrinn polymerized with beetroot fibers (Bio-polymer), was prepared and applied to the removal of organic and inorganic contaminants from wastewater. An investigation into the use of cross-linked cyclodextrin polyurethanes copolymerised with beetroot fibers as adsorbents for organic pollutants and heavy metals has yielded very useful results which may have an impact in future water treatment applications.

The Biopolymer was tested in water contaminated by dyes, polycyclic aromatic hydrocarbons (PAH) and heavy metals. The effectiveness to eliminate dyes such as methylene blue and Rhodamine B with concentrations around $100 \mathrm{ppm}$ was more than $99 \%$, while the pyrene, which was chosen as an example among PAHs, showed a potential of elimination exceeding the $97 \%$ for solutions of $10 \mathrm{ppm}$. Also, heavy metals, such as Lead, Zn, and $\mathrm{Cu}$, were tested and showed an efficacy exceeding the 99.8\%. The results indicated that the biopolymer developed in this study has the potential to be a promising material for the removal of mixed pollutants from industrial wastewater or from contaminated groundwater.
\end{abstract}

Keywords: $\beta$-cyclodextrin-polyurethane, beetroot fibers, remediation, water, heavy metals, dyes

\section{Introduction}

Traditional techniques for the removal of heavy metals, such as chemical precipitation, chemical oxidation, chemical reduction, ion exchange, filtration, electrochemical treatment and reverse osmosis gives rise to several problems, such as elimination of metal ions and the random generation of toxic sludge that are often difficult to dewater and require extreme caution in their disposal (Xia \& Liyuan 2002; Hanjuan et al., 2010; Silva et al., 2009). Moreover, these classical techniques for heavy-metal removal are extremely expensive cost due to the high reagent or energy requirements (Xia \& Liyuan, 2002). The need for economical, effective and safe methods for removing heavy metals from wastewater has resulted in search for unconventional methods that may be useful in reducing the levels of accumulated heavy metals in the environment. Using microbial biomass as biosorbents for heavy metal removal from industrial waste streams has been considered as a potential alternative technology. Most microbial biomasses have a negative charge owing to the presence of negatively charged groups of atoms on the cell membrane and cell wall. The charged groups or ligands are responsible for the adsorption of positively charged metal ions in solution. The adsorption is typically rapid, reversible and independent of temperature and energy metabolism. This phenomenon is known as biosorption. Biosorption, using biomaterials such as bacteria, fungi, yeast and algae, is regarded as a cost-effective biotechnology for the treatment of high volume and low concentration complex wastewaters containing heavy metals. Currently, several adsorbents are being used including seaweeds, molds, yeast, bacteria, crab shells, agricultural products which are by-products of agriculture and industries. It has been demonstrated that some fungal and bacterial species are typically associated with heavy metal rich substrata and can be even considered as hyper accumulators of heavy metals (Purvis \& Halls, 1996; Gadd, 1993). Fungi offer a wide range of chemical groups that can attract and sequester heavy metals in their biomass. Potential of filamentous fungi in bioremediation of 
industrial effluents and waste waters containing heavy metals has been increasingly reported from different parts of the world (Gadd, 1996). Removal of organic compounds from water remains a big challenge for municipalities and water authorities. Such organic compounds, which include polychlorinated biphenyls (PCBs), polyaromatic hydrocarbons (PAHs), dioxins and endocrine disrupting compounds EDCs can be toxic and pose serious health risks to humans and animals (Comerton et al., 2009). Techniques such as the use of activated carbon, zeolites and reverse osmosis are currently being used to treat water before consumption. However, activated carbon fails to remove many organic pollutants at concentration levels of nanograms per liter (Li \& Ma, 1999). Zeolites also show low affinity for organic compounds and reverse osmosis is currently too expensive for wide spread use (Li \& Ma, 1999). Thus, an effective and economical method to remove these organic pollutants to safe concentration levels is often required.

Cyclodextrin polymers have demonstrated the capacity to remove organic species in water at concentration levels as low as $\mathrm{ng}^{-1}$ ( $\mathrm{Li} \& \mathrm{Ma}, 1999$; Mamba et al., 2007) .Furthermore, it was found that these polymers could be recycled several times while still maintaining high adsorption efficiency (Mhlanga et al., 2007; Michael et al., 2012).

The objective of this work is to investigate the potential properties of the $\beta$-cyclodextrin polyurethane by its affinity to the organic pollutants and of the beetroot fibers by its capacities to retain inorganic compounds. The combination of those two properties leads us to synthesis $\beta$-cyclodextrin polyurethane polymerized with beetroot fiber. The beetroot fiber removes the heavy metals while the $\beta$-cyclodextrin polyretrhane eliminates organic compounds.

\section{Experimental}

\subsection{Material}

Sugar beets were collected from industries in Lebanon Bekaa, air dried and crushed to powder in a mill. The meal obtained was sieved through a sieve of $100 \mathrm{um}$. The fiber powder was soaked in distilled water for 24 hours at room temperature, and air-dried and stored for use. All reagents used for the preparation of solutions were of analytical grade. $\mathrm{CuSO}_{4} \cdot 5 \mathrm{H}_{2} \mathrm{O}, \mathrm{NiSO}_{4} \cdot 6 \mathrm{H}_{2} \mathrm{O}, \mathrm{Pb}\left(\mathrm{NO}_{3}\right)_{2}, \mathrm{ZnCl}_{2}, \mathrm{HCl}(a q)$, were purchased from Prolabo and used without further purification. Toluene diisocyanate (TDI), pyridine and $\beta$-cyclodextrin were purchased from sigma.

\subsection{Instruments}

Metals were analyzed by atomic absorption spectrometry (Perkin Elmer 5000 and Shimadzu A-6800). The IR spectrum was recorded on a FTIR spectrometer (UNICAM). The Shimadzu UV-1601 UV-VIS spectrometer was used in the range from $190 \mathrm{~nm}$ to $1100 \mathrm{~nm}$ to monitor the organics removal by the bio-polymer filter the $\mathrm{pH}$ values were measured with a WTW $\mathrm{pH} / \mathrm{mV}$ Hand-Held Meter 330/SET. The $\mathrm{pH}$ meter was calibrated by using pH-Buffer solutions.

\subsection{Preparation of the $\beta$-Cyclodextrin Polyurethanes Polymerized with Beetroot Fibers (Bio-Polyurethane)}

In a $1000 \mathrm{ml}$ Erlenmeyer flask, $60 \mathrm{~g}$ of $\beta$-CD were dissolved by stirring in $300 \mathrm{ml}$ of pyridine at a temperature of $70^{\circ} \mathrm{C}$. To this solution, $28 \mathrm{~g}$ of beetroot fiber $(100 \mu \mathrm{m})$ were added and stirred until homogenization of the mixture. Then $100 \mathrm{ml}$ of TDI (toluene diisocyanate) were added gradually in the solution. An off white solid starts to appear called $\beta$-cyclodextrin polymer-fibers or polyruethane reinforced by beetroot fiber (Bio-polymer). The reaction time was $30 \mathrm{~min}$. The off white solid obtained was washed with water to remove pyridine remaining in the material and an additional washing with ethanol was done to improve removal of pyridine. For more security we have washed the bio-polymer with water and ethanol five times to remove completely the traces of pyridine.

Schematic reaction of the polymerization of $\beta$-cyclodextrin, toluene diisocyanate (TDI), and beetroot fibers in pyridine as solvent at $70^{\circ} \mathrm{C}$ is described as follow.

Schematic presentation of the $\beta$-cyclodextrin polyurethane beetroot polymer: 

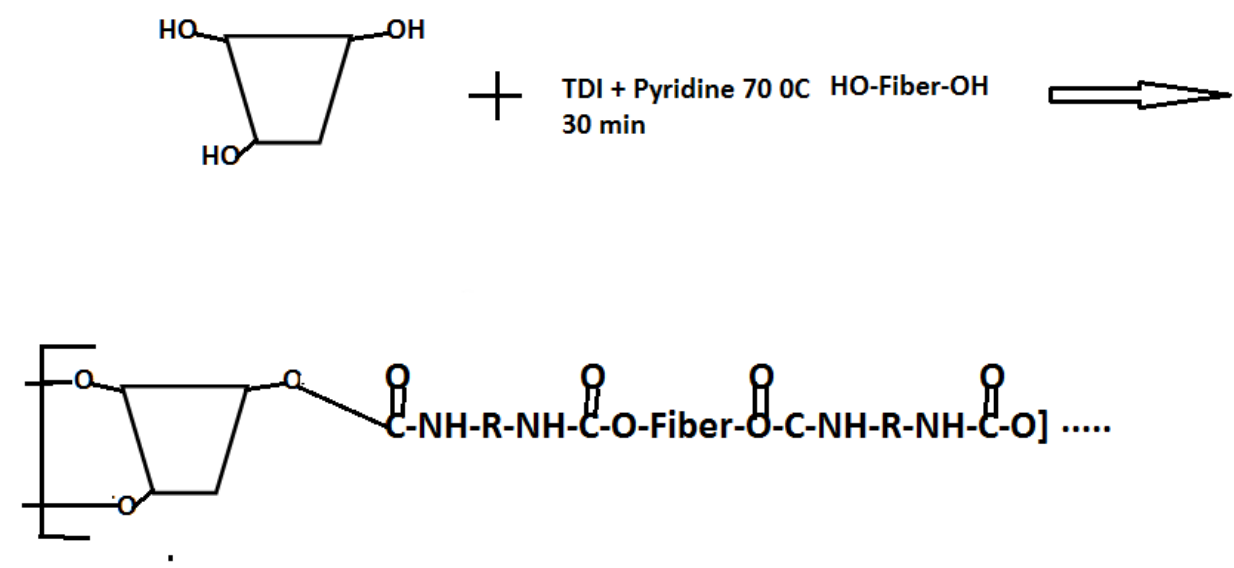

\subsection{Column Procedures to Remove Dyes and Heavy Metals}

The column consisted of a Plexiglas tubing $(30 \mathrm{~cm}$ height, $\varphi 4.0 \mathrm{~cm})$ perforated at the bottom and connected to a pumping system. In order to assure homogeneity and reproducibility of the results, the column was filled for all experiments by $30 \mathrm{~g}$ of bio-polmer. Also, we proceeded with the passage of $50 \mathrm{~mL}$ of solution, through the bio-polymer filter and we have made about 10 passages from the same initial solution to study the saturation of the Bio-filter.

Heavy metal solutions of different concentrations (100 ppm) were prepared . Methylene blue was choose as a dye example at the concentration of $(100 \mathrm{ppm})$. The $\mathrm{pH}$ values were adjusted by the addition of aqueous $\mathrm{HCl}$ solutions. Pyrene standard solution was prepared in ethanol/water 50/50 (v/v) with a concentration of $30 \mathrm{mg} /$ L.

\section{Results and Discussion}

\subsection{Beetroot Chemical Composition}

The percentage average of the different components of beetroot fibers are respectively $25 \%$ of cellulose, $5 \%$ of lignin, 30\% pectin, and 40\% hemicelluloses (Dinand et al., 1996) The materials contain several chemical functions like hydroxyl, carboxylic, aldehyde, ketone, $\mathrm{C}=\mathrm{N}$ as shown in the FTIR of the fibers in Figure 1. The chemical functions will play an important role in the complexation of heavy metals on the surface of fibers.

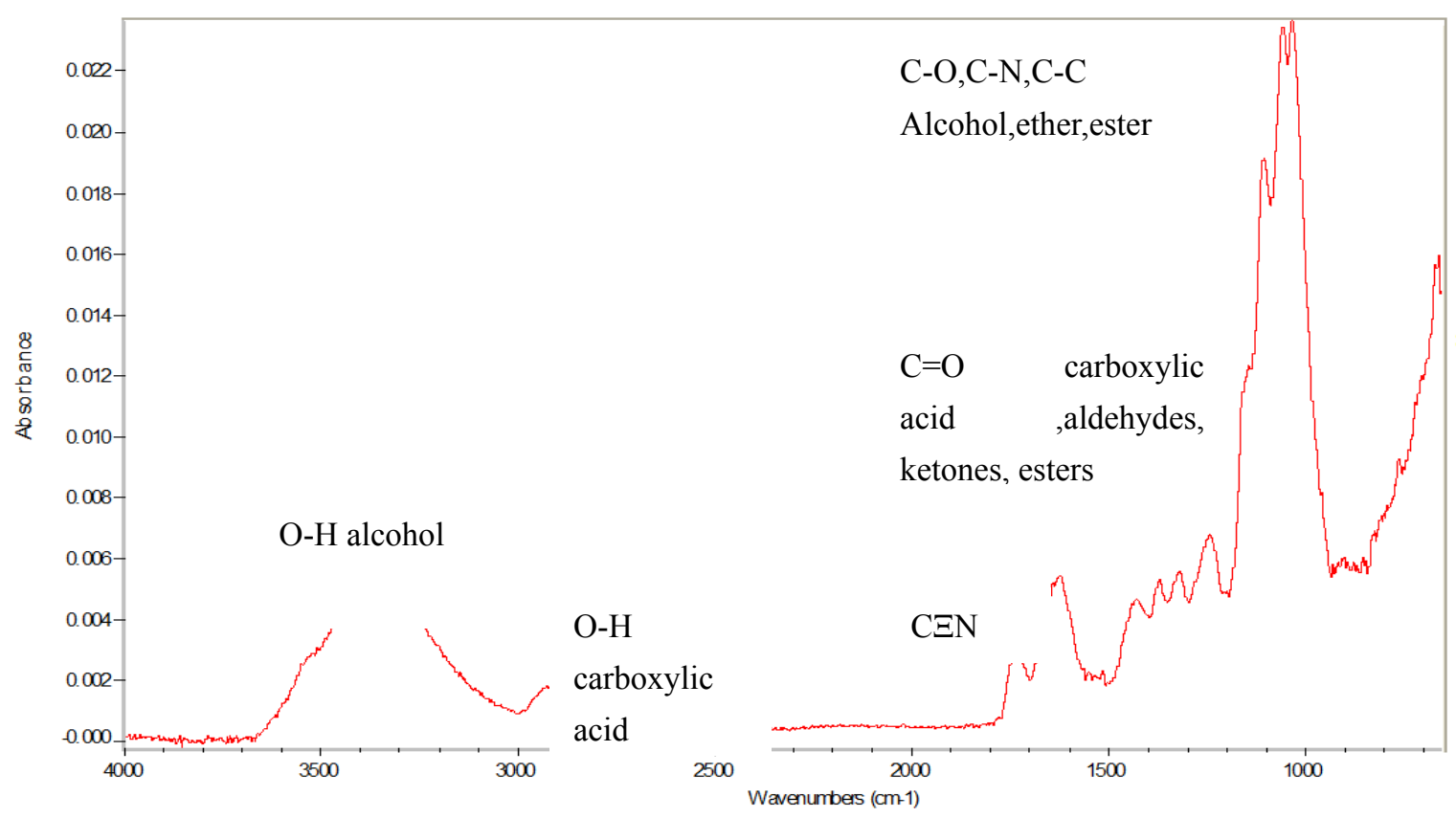

Figure 1. FTIR of beetroot fibers, showing the chemical functions at the surface of fibers 


\subsection{Effect of pH on the Heavy Metals Retention Efficiency}

In order to study the effect of $\mathrm{pH}$ on the retention efficiency of the bio-filter, we have prepared for each metal cation $(\mathrm{Pb}, \mathrm{Cu}$ and $\mathrm{Zn})$, several solutions at the same concentration $(100 \mathrm{ppm})$, but with different $\mathrm{pH}$ values ranging from 1.5 to 7 . For each solution we determined the maximum of metal retention in function of $\mathrm{pH}$. The plot ( $\%$ of the retention in function of $\mathrm{pH})$ is presented in Figure 2.

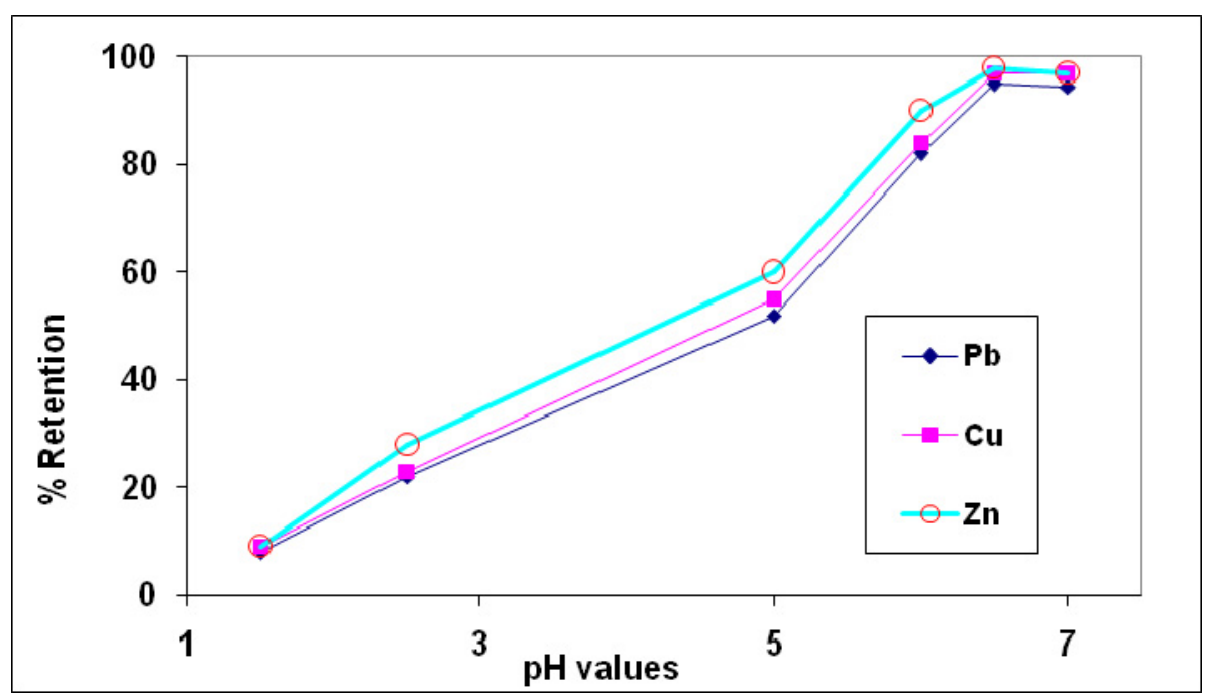

Figure 2. Retention efficiency of biopolymer vs $\mathrm{pH}$ values of the aqueous solutions (100 ppm)

According to Figure 2, we observe that the maximum retention for all cations appear in the region between $\mathrm{pH} 6$ and 7. At $\mathrm{pH}=6.5$ the maximum retention detected for cations are as follows: $100 \%$ for lead, $99 \%$ zinc, $98 \%$ copper.

\subsection{Encapsulation Efficiency of Methylene Blue in $\beta$-Cyclodextrin Cavities}

\subsubsection{Association Constant Calculation}

The absorption spectra were recorded in the range of 500-750 nm and the absorbance was determined at $661 \mathrm{~nm}$. The intrinsic binding constants of $\mathrm{MB}$ with $\beta-\mathrm{CD}$, were determined by absorption titrations. The intrinsic binding constant $(k)$ was determined from the plots of $C / \Delta \varepsilon_{a p}$ versus $C$ according to the Equation (1) (Kumar et al., 1993):

$$
\text { Equation(1) } \mathrm{C} / \Delta \varepsilon_{a p}=\mathrm{C} / \Delta \varepsilon+1 /(\Delta \varepsilon \mathrm{k})
$$

where,

$C$ is the concentration of $\beta-\mathrm{CD}, \Delta \varepsilon_{\mathrm{ap}=\mid} \varepsilon_{\mathrm{a}}-\varepsilon_{\mathrm{f}} \mid$, and $\Delta \varepsilon_{=\mid} \varepsilon_{\mathrm{b}}-\varepsilon_{\mathrm{f}} \mid$

$\boldsymbol{\varepsilon}_{\boldsymbol{a}}$ (the apparent extinction coefficient) is obtained by calculating $A_{a b s} /[M B]$.

$\varepsilon_{\mathrm{b}}$ and $\varepsilon_{f}$ correspond to the extinction coefficient of the bound form of MB and the free form of MB, respectively. From Equation (1), the slope equal to $1 / \Delta \varepsilon$ and the $y$-intercept equal to $1 / \Delta \varepsilon \mathrm{k}$ and $k$ was obtained from the ratio of the slope to the $y$-intercept, changes of the absorption spectra of MB were obtained when the concentration of $\beta$-CD changes.(results not shown). The absorption spectra of MB upon increasing the concentration of $\beta-C D$ showed a strong increase in the peak intensities. When the concentration of $\beta-C D$ increased from 0.1 mmol. $1^{-1}$ to $3 \mathrm{mmol}^{-1} \mathrm{l}^{-1}$, significant changes where observed in the absorbance intensities of $\mathrm{MB}\left(10 \mu \mathrm{mol} . \mathrm{I}^{-1}\right)$ at $\mathrm{pH}=7.3$.

Using the intrinsic binding constants and plotting) $\mathrm{C} / \Delta \varepsilon_{a p}$ versus $\mathrm{C}$ the constant values founds was $\mathrm{k}=4.46 \times 10^{3}$ 1.mol ${ }^{-1}$.

The linear correlation coefficient suggested that the experimental data corresponded well to Eq. (1), revealing that the inclusion complex was a 1:1 association (Kumar et al., 1993; Cramer, 1967; Wang, 1994).

We estimated that the constant $\mathrm{k}$ between $\mathrm{MB}$ and $\beta$-CD should remain approximately the same between the polymer $\beta$-CD and MB. 


\subsubsection{Effect of $\mathrm{pH}$ on the Constant Association of Methylene Blue in Cyclodextrin Cavities}

The association constants of MB / $\beta$-cyclodextrin were determined for the same concentration of MB (10 $\mu$ mol..$^{-1}$ ) but the concentration of $\beta$-cyclodextrine was changed as mentioned above.

It has been observed that the maximum value of the constant association was achieved, when the $\mathrm{pH}=6.8$.

Figure 3 shows a plot of $\mathrm{k}$ (association constant) versus $\mathrm{pH}$.

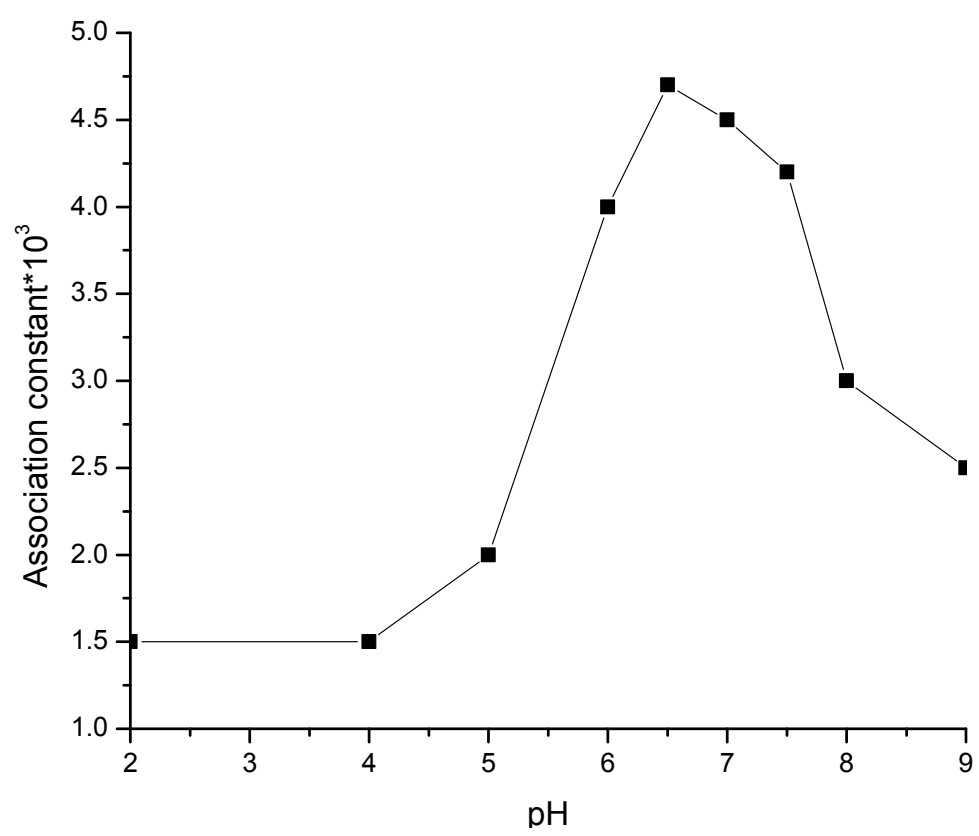

Figure 3. Effect of $\mathrm{pH}$ on the constant association of $\beta$-cyclodextrin and methylene blue

This results show that at low and high $\mathrm{pH}$ it was observed that the hydrophobic characters of the cavity decreases and accordingly the maximum encapsulation is surrounding $\mathrm{pH} 6$ and 7. This is why it is necessary to adjust the $\mathrm{pH}$ of contaminated water in this domain of acidity in order to use the bio-filter $\beta$-cyclodextrin polyurethane with beetroot fibers in the field of remediation.

\subsection{Retention Efficiency of Heavy Metals by the Bio-Polymer}

The bio-filter was first tested to remove some metallic cations from a model solution containing different cations. This model solution was a mixture of lead, zinc, nickel and copper cations. The total concentration was $200 \mathrm{ppm}$ (50 ppm of each). Figure 4 shows that after 10 passages, the retention efficiency of the bio-filter varied from: $100 \%$ to $95 \%$ for lead, $99 \%$ to $90 \%$ for zinc, $99 \%$ to $85 \%$ for copper and from $99 \%$ to $75 \%$ for nickel. 


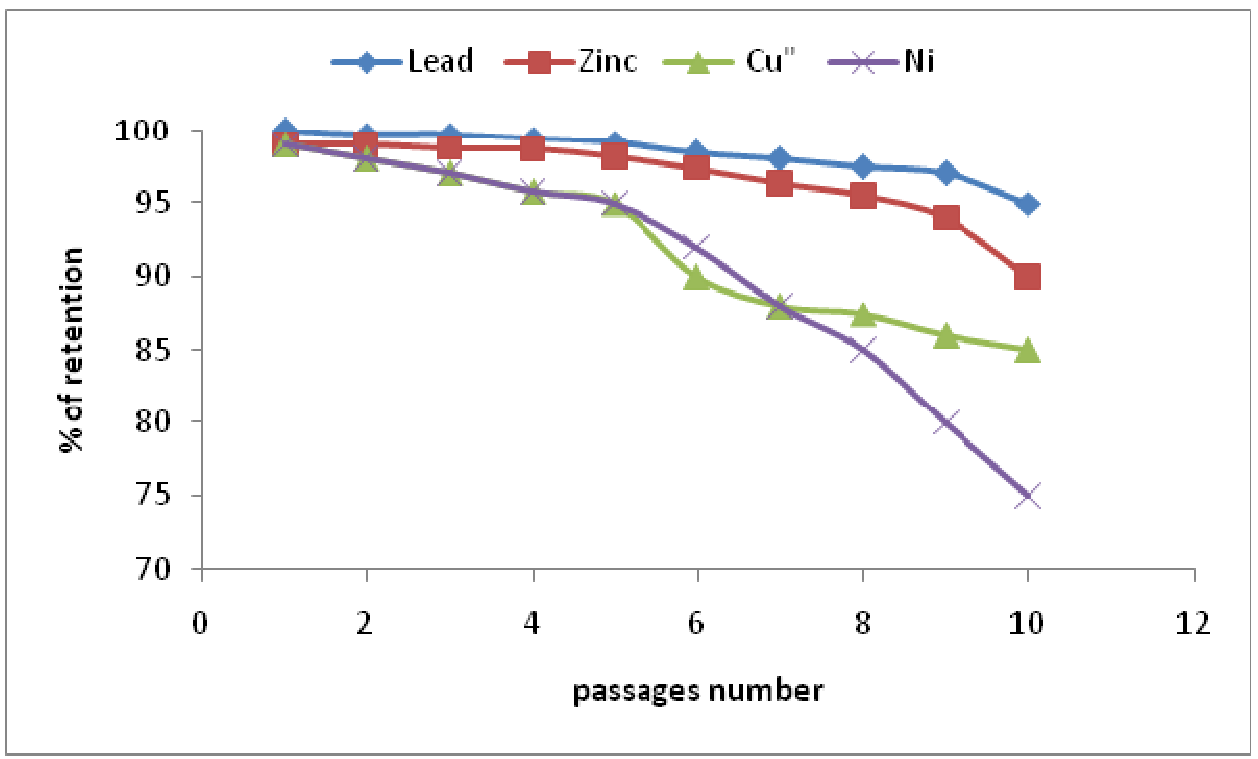

Figure $4 . \%$ retention of heavy metals in a mixture of a model solution after ten passages of the initial concentration

\subsection{Removal Efficiency of Organic Pollutants by the Biopolymer}

The solutions models are: methylene blue, Rhodamine B and Pyrene. Methylene blue, Rhodamine B, were used to test the remediation of water polluted by dyes, while the Pyrene was used as a polycyclic aromatic hydrocarbon example. They are chosen because they present significant sources of industrial pollutionThe experimental results showed that the biopolymer is able to eliminate the dyes at the concentration of $100 \mathrm{ppm}$ such as methylene blue or rhodamine B, with an efficiency of $99 \%$.

In order to test the effectiveness of the biopolymer in the treatment of water polluted by PAHs, we injected a solution of pyrene prepared in solvent-ehanol water at a concentration of $30 \mathrm{ppm}$ in the biopolymer. The concentrations before and after the injection were measured by UV spectroscopy.

Figure 5 shows the UV spectra of pyrene solution before and after injection inside the biopolymer). It is also obviously that the removal of pyrene is efficient and the removal percentage is higher than $98 \%$.

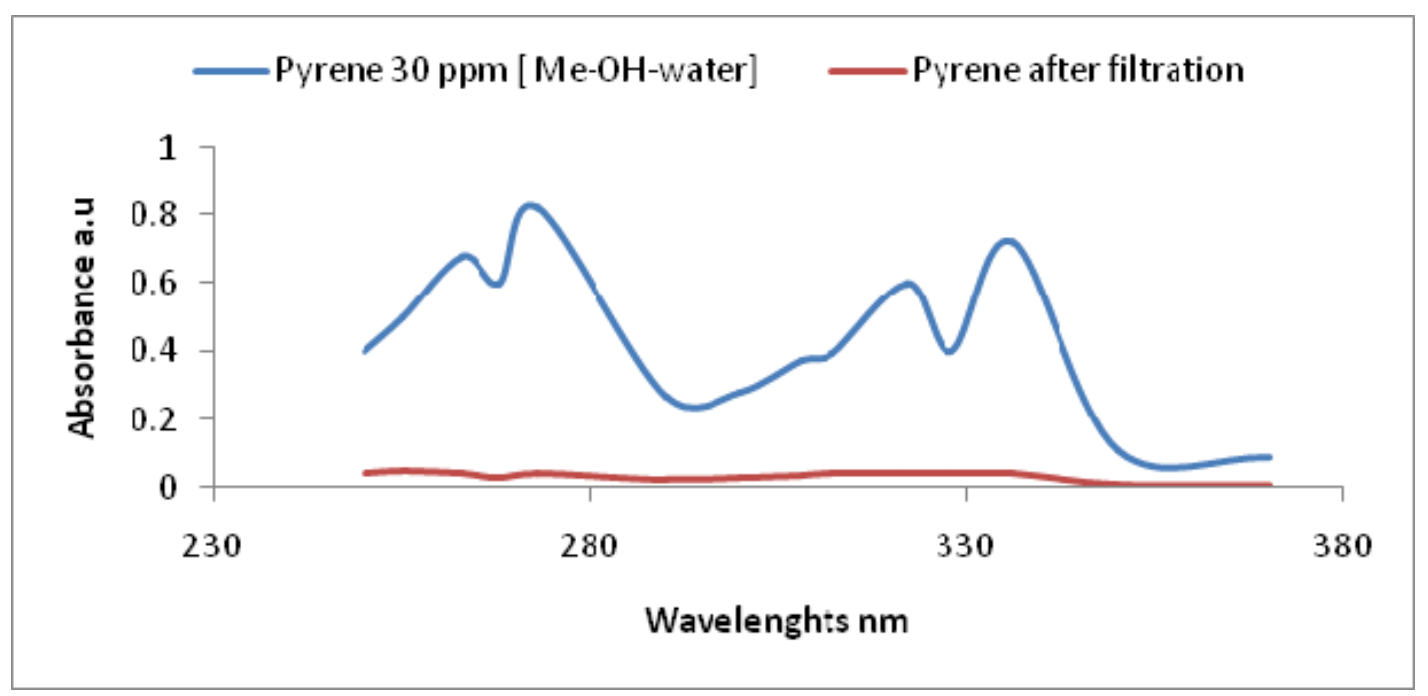

Figure 5. UV-Vis absorption spectra of Pyrene before and after filtration through the $\beta$-cyclodextrin polyurethane polymerized with beetroot fibers 


\subsection{Comparative Study with Biopolymer}

Comparing the biopolymer technology with others, we will be able to highlight the benefits offered by the biopolymer. Biopolymer advantages reside firstly in the ability to eliminate heavy metals and organic pollutants during the same operation. Secondly the biopolymer can be re-used hundreds of times after his regeneration when it is saturated

However most microbial biomasses have, a negative charge and then the charged groups or ligands are responsible for the adsorption of positively charged metal ions in solution. Moreover the hydrophobic molecules couldn't be absorbed by this biomasses.

It has been demonstrated that some fungal and bacterial species are typically associated with heavy metal rich substrata and can be even considered as hyper accumulators of heavy metals (Purvis \& Halls, 1996; Gadd, 1993). Techniques such as the use of activated carbon, zeolites and reverse osmosis are currently being used to treat water before consumption. However, activated carbon fails to remove many organic pollutants at concentration levels of nanograms per liter and it fails also to remove heavy metals. Zeolites show low affinity for organic compounds and reverse osmosis is currently too expensive for wide spread use (Li \& Ma, 1999).

Recently (Salipira et al., 2007) used polymer of polyurethane with nanotube carbon to remove the organics from water but this materials was not tested to remove the heavy metals. At our knowledge this is the first time, a biopolymer was used to remove organic and inorganic from wastewater during the same operation.

\section{Conclusion}

Based on the results of this study, we can conclude that this work has shown successes and opened possibilities for several applications.

$\beta$-cyclodextrin polyurethane co-polymerized with beetroot fibers (bio-polymer) have been synthesized from $\beta$-cyclodextrin, beetroot fibes and TDI in pyridine as solvent which subsequently be removed by washing.

Contrary to the $\beta-\mathrm{CD}$ which is soluble in water, the synthesized biopolymer is insoluble in water and in organic solvents such as DMF, $\mathrm{CH}_{3} \mathrm{OH}$ and $\mathrm{CH}_{2} \mathrm{Cl}_{2}$.

This property is very important because it is generally used to allow their application in water treatment.

Biopolymers have been effective for the removal of organic and inorganic pollutants from contaminated water.

The Capacities of elimination were determined for certain dyes and PAH compounds and inorganics.

For both situations the removal efficiencies were higher than $95 \%$ for organic and greater than $98 \%$ for inorganic.

\section{References}

Comerton, A. M., Andrews, R. C. D., \& Bagley, M. (2009). Practical overview of analytical methods for endocrine-disrupting compounds, pharmaceuticals and personal care products in water and wastewater. Philosophical Transactions of Royal Society A, 367(1904), 3923-3939.

Cramer, F., Saenger, W., \& Spatz, H. C. (1967). J. Am. Chem. Soc., 89, 14. http://dx.doi.org/10.1021/ja00977a003

Dinand, E., Chanzy, H. M., \& Vignon, R. (1996). Parenchymal cell cellulose from sugar beet pulp: preparation and properties. Cellulose, 3, 183-188. http://dx.doi.org/10.1007/BF02228800

Gadd, G. M. (1993). Interactions of fungi with toxic metals. New Phytol., 124, 25-60. http://dx.doi.org/10.1111/j.1469-8137.1993.tb03796.x

Guo, H, Luo, S, Chen, L, Xiao, X, Xi, Q, Wei, W, ... He, Y. (2010). Bioremediation of heavy metals by growing hyper-accumulator endophytic bacterium Bacillus sp. L14. Bioresource Technology, 101, 8599-8605. http://dx.doi.org/10.1016/j.biortech.2010.06.085

Kumar, C. V., \& Asuncion, H. E. (1993). J. Am. Chem. Soc., 115, 8547. http://dx.doi.org/10.1021/ja00072a004

Li, D., \& Ma, Q. (1999). From inclusion chemistry to water purification technology. Chemtech, 35, 31-37.

Mamba, B., Krause, W., Malefetse, T. J., Mahlanga, S. D., \& Salipira, N. (2007). Removal of geosmin and 2-methylisorboneol (2-MIB) in water from Zuikerbosch Treatment Plant (Rand Water) using B-cyclodextrin polyurethanes. Water $S A, 33,223-227$. 
Mhlanga, S. D., Mamba, B., Krause, M., \& Malefetse, T. J. (2007). Removal of organic contaminants from water using nanosponge cyclodextrin polyurethanes. J. Chem. Technol. Biotechnol, 82, 382-388. http://dx.doi.org/10.1002/jctb.1681

Michael, A., \& Jackson, M. A. (2012). Sorption of Ochratoxin A from Aqueous Solutions Using ß-Cyclodextrin-Polyurethane Polymer. Toxins, 4, 98-109. http://dx.doi.org/10.3390/toxins4020098

Purvis, O. W. C., \& Halls, A. (1996). Review of lichens of metalliferous rocks. Lichenologist, $28,571-601$. http://dx.doi.org/10.1017/S0024282996000758

Salipira, K. L., Mamba, B. B., Krause, R. W., Malefetse, T. J., \& Durbach, S. H. (2007). Carbon nanotubes and cyclodextrin polymers for removing organic pollutants from water. Environ. Chem. Lett., 5, 13-17. http://dx.doi.org/10.1007/s10311-006-0057-y

Silva ,B., Figueiredo, H., Neves, I. C., \& Tavares ,T. (2009). The role of pH on Cr (VI) Reduction and Removal by Arthrobacter Viscosus. International Journal of Chemical and Biological Engineering, 2(2), 100-103.

Wang, X. M., \& Chen, H. Y. (1994). Spectrochim. Acta Part A, 51, 333. http://dx.doi.org/10.1016/0584-8539(94)00137-Z

Wang, X. M., Chen, H. Y., Li, S. Y., \& Wang, J. D. (1994). Spectroscop. Lett., $27,499$. http://dx.doi.org/10.1080/00387019408007254

Xia, Y., \& Liyuan, C. (2002). Study of gelatinous Supports for Immobilizing Inactivated Cells of Rhizopus oligosporus to Prepare Biosorbent for Lead Ions. The International Journal of Environmental Studies, 5, $1-6$. 